Provided for non-commercial research and education use. Not for reproduction, distribution or commercial use.

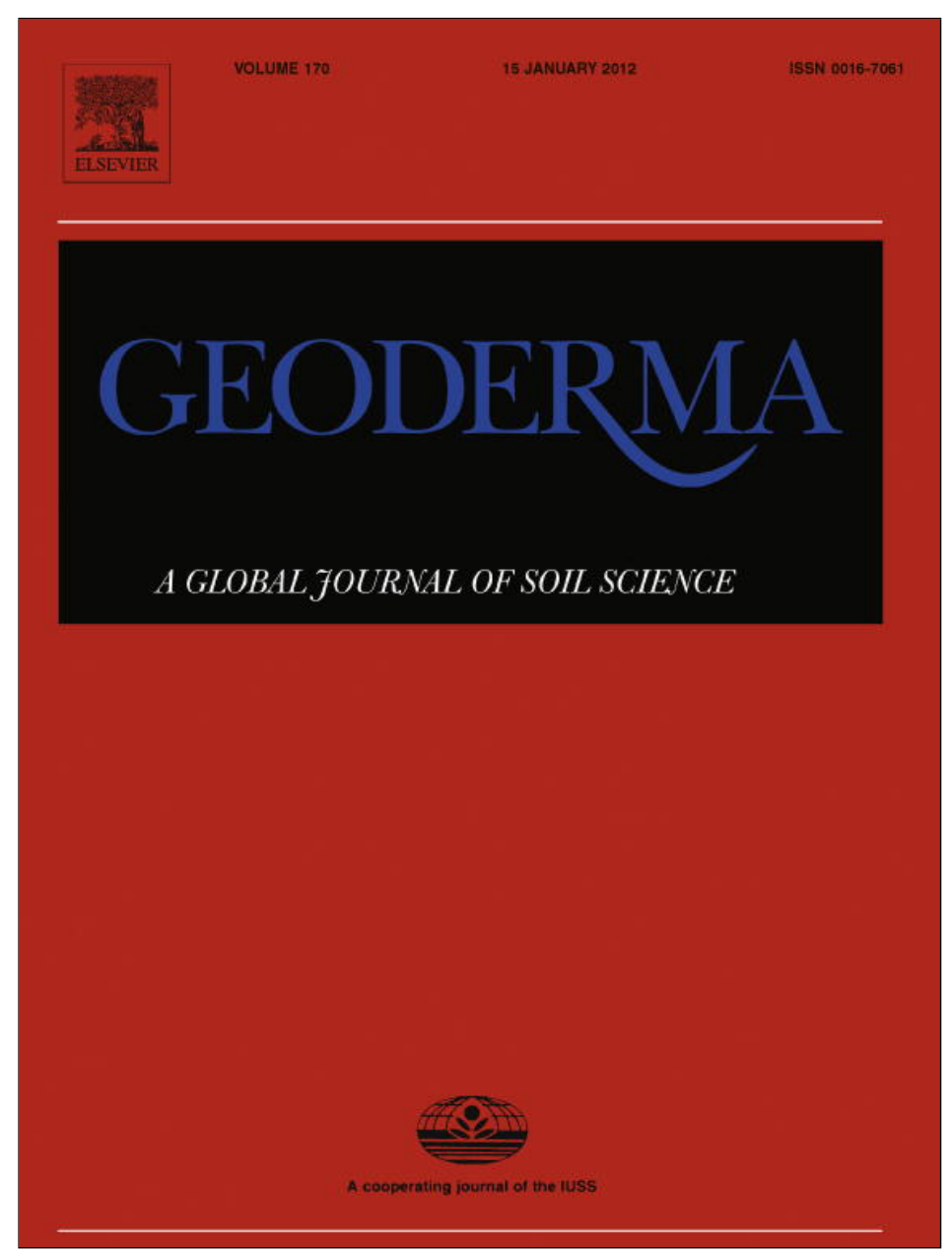

(This is a sample cover image for this issue. The actual cover is not yet available at this time.)

This article appeared in a journal published by Elsevier. The attached copy is furnished to the author for internal non-commercial research and education use, including for instruction at the authors institution and sharing with colleagues.

Other uses, including reproduction and distribution, or selling or licensing copies, or posting to personal, institutional or third party websites are prohibited.

In most cases authors are permitted to post their version of the article (e.g. in Word or Tex form) to their personal website or institutional repository. Authors requiring further information regarding Elsevier's archiving and manuscript policies are encouraged to visit:

http://www.elsevier.com/copyright 


\title{
Geochemical characteristics of rare earth elements (REEs) in the paddy soil and rice (Oryza sativa L.) system of Kočani Field, Republic of Macedonia
}

\author{
Nastja Rogan Šmuc ${ }^{\text {a,* }}$, Tadej Dolenec ${ }^{\text {a }}$, Todor Serafimovski ${ }^{b}$, Matej Dolenec ${ }^{\text {a }}$, Petra Vrhovnik ${ }^{a}$ \\ a Faculty of Natural Sciences and Engineering, University of Ljubljana, Department of Geology, Aškerčeva 12, 1000 Ljubljana, Slovenia \\ b Faculty of Mining, Geology and Polytechnics, University “Goce Delcev - Stip”, Goce Delcev 89, 2000 Stip, Republic of Macedonia
}

\section{A R T I C L E I N F O}

\section{Article history:}

Received 20 April 2010

Received in revised form 21 January 2012

Accepted 6 March 2012

Available online $\mathrm{xxxx}$

\section{Keywords:}

Rare earth elements (REEs)

Paddy soils

Rice (Oryza sativa L.)

Distribution

Sequential extraction procedure

Republic of Macedonia

\begin{abstract}
A B S T R A C T
In the Republic of Macedonia, information about rare earth elements (REEs) distribution patterns, transportation and speciation characteristics (from soil to plants) is very rare. Therefore, the concentrations of REEs in Kočani paddy soils and rice samples from the Republic of Macedonia were measured and evaluated. The elevated concentrations of REEs in paddy soils can be explained by contributions from acidic and intermediate igneous rocks, which are one of the main source materials for Kočani paddy soils. Low percentages of REEs were bound to the water-soluble and exchangeable fractions, revealing low mobility of REEs in the investigated paddy soils. Furthermore, small amounts of REEs were detected in rice (Oryza sativa L.) grain samples. The calculated transfer values (TF) for REEs in rice samples were also very low, confirming a small accumulation of REEs (La, Ce, Pr, Nd and Sm) by the studied crops and in the Kočani soil-plant system.
\end{abstract}

(C) 2012 Elsevier B.V. All rights reserved.

\section{Introduction}

Rare earth elements (REEs) are a group of 15 elements of which only promethium $(\mathrm{Pm})$ does not occur naturally in the Earth's crust (Kabata-Pendias and Pendias, 2001). From a geochemical perspective, REEs are not particularly rare; in fact, in the average crust sample, they are as abundant as $\mathrm{Cu}, \mathrm{Pb}$, and $\mathrm{Zn}$ and have higher concentrations than Sn, Co, Ag, and Hg (Wang et al., 1998). REEs are divided into two sub-groups: (1) lanthanum to samarium (with lower atomic numbers and masses), referred to as light rare earth elements (LREEs), and (2) europium to lutetium (with higher atomic numbers and masses), referred to as heavy rare earth elements (HREEs).

REEs have similar chemical and physical properties and tend to exist together naturally rather than in isolation, which explains their very similar behaviour in the environment (Henderson, 1984; Hu et al., 2006; Tyler, 2004). Their use as proxies is applied in different disciplines of the earth sciences, especially hydrology, geochemistry, and geology (Aubert et al., 2004; Egashira et al., 1997; Han and Liu, 2006; Henderson, 1984; Hu et al., 2006; Li et al., 1998; Protano and Riccobono, 2002; Tyler, 2004; Wang et al., 2004).

REEs have been characterised neither as essential elements for life nor as strongly toxic elements in the environment (Hu et al.,

\footnotetext{
* Corresponding author. Tel.: + 3861470 4500; fax: + 38614704560.

E-mail addresses: nastja.rogan@guest.arnes.si (N.R. Šmuc),

tadej.dolenec@ntf.uni-lj.si (T. Dolenec), todor_s2000@yahoo.co.uk,

goranktasev@yahoo.com (T. Serafimovski), matej.dolenec@ntf.uni-lj.si (M. Dolenec), petra.vrhovnik@gmail.com (P. Vrhovnik).
}

2006; Laveuf and Cornu, 2009; Tyler, 2004). Much less interest has been paid to them than to several transition and other heavy metals.

Until recently, little information had been available for estimating the environmental and ecological impacts of REEs, and such information was generally scarce and sometimes contradictory (Aubert et al., 2004; Chen, 1993; Egashira et al., 1997; Han and Liu, 2006; Henderson, 1984; Hu et al., 2006; Li et al., 1998; Markert and Zhang, 1991; Wang, 1991a,b; Wang et al., 2004). Therefore, it is important to obtain more knowledge about the different environmental effects of REEs to predict possible deleterious effects.

Highly elevated concentrations of REEs such as La, Ce, Sm, Eu and $\mathrm{Tb}$ have already been found in several industrial, urban (Yoshida et al., 1998), and agricultural soils (Ding et al., 2006; Hong et al., 2000; Hu et al., 2006; Tsumura and Yamasaki, 1993). When evaluating the true short- and long-term environmental impacts of REEs present in soils, one of the most crucial factors to consider is the mobility characteristics of REEs. However, the soluble, exchangeable, and chelated REE species in soils are the only labile fractions available to plants (Kabata-Pendias and Pendias, 2001). A widely used method to identify and evaluate the availability of REEs in soils is soil leaching by means of chemical extractants. Among the various sequential procedures presented, the most widely applied is that proposed by Tessier et al. (1979).

In the Republic of Macedonia, information about REE distribution patterns, transportation and speciation characteristics (from soil to plants) is also very rare, especially with regard to the agricultural and mining province Kočani, located in the eastern part of the Republic of 
Macedonia (Dolenec et al., 2007; Rogan Šmuc, 2010). In this context, the main objectives of the present research are as follows:

- to estimate the content and distribution patterns of REEs in the paddy soils and rice crops of Kočani Field and

- to assess the mobility and bioavailability characteristics of REEs in paddy soil samples.

\section{Materials and methods}

\subsection{Study area}

Kočani Field is located in eastern Macedonia, approximately $32 \mathrm{~km}$ from the city of Štip and $115 \mathrm{~km}$ from the capital city Skopje. With an average length of $35 \mathrm{~km}$ and a width of $5 \mathrm{~km}$, Kočani Field lies in the Bregalnica River Valley between the Osogovo Mountains in the north and the Plačkovica Mountains in the south (Fig. 1).

The broader region is well-known as an agricultural and mining province with $\mathrm{Pb}-\mathrm{Zn}$ mines in Sasa and Zletovo, and the area has significant thermal activity. The most important agricultural products of the region are rice, maize, tomatoes, cucumbers, red peppers, and other vegetables.

The Bregalnica River, together with its tributaries, is the principal drainage system of the investigated area and is, therefore, an important water supply for the irrigation of the surrounding paddy fields. The main tributaries of the Bregalnica River are the Kamenica River in the northeastern part of the study area and the Zletovska River on the western side of Kočani Field (Fig. 1).

The paddy soil of Kočani Field was estimated to originate from the composite material of the sediment derived from igneous, metamorphic, and sedimentary rocks located in the Kočani region. The sediment material was transported by the Bregalnica River and its tributaries and was deposited in the Kočani depression (Dolenec et al., 2007; Serafimovski and Aleksandrov, 1995).

The exposed lithologies of Kočani Field are predominantly composed of acidic to intermediate volcanic rocks (dacite ignimbrites, andesite ignimbrites, augite-hornblende-biotite andesite, andesitic tuffs, and breccias) as well as lithologies that are metamorphic (amphibolites, gneisses, various schists, phyllites, and rare marbles), basic (granites, gabbros and basalts) and, to a lesser extent, sedimentary (conglomerates, sandstones, claystones, and limestones) (Serafimovski and Aleksandrov, 1995). Consequently, the soil mineralogy and elemental compositions are closely related to the acidic and intermediate rocks of the Kočani region (Dolenec et al., 2007).

\subsection{Paddy soil sampling and analysis}

The sampling of the paddy soils was conducted in the autumn of 2005. The sampling locations are shown in Fig. 2. Paddy soil samples were collected from 38 locations from seven profiles across Kočani Field (Sections I-VII).

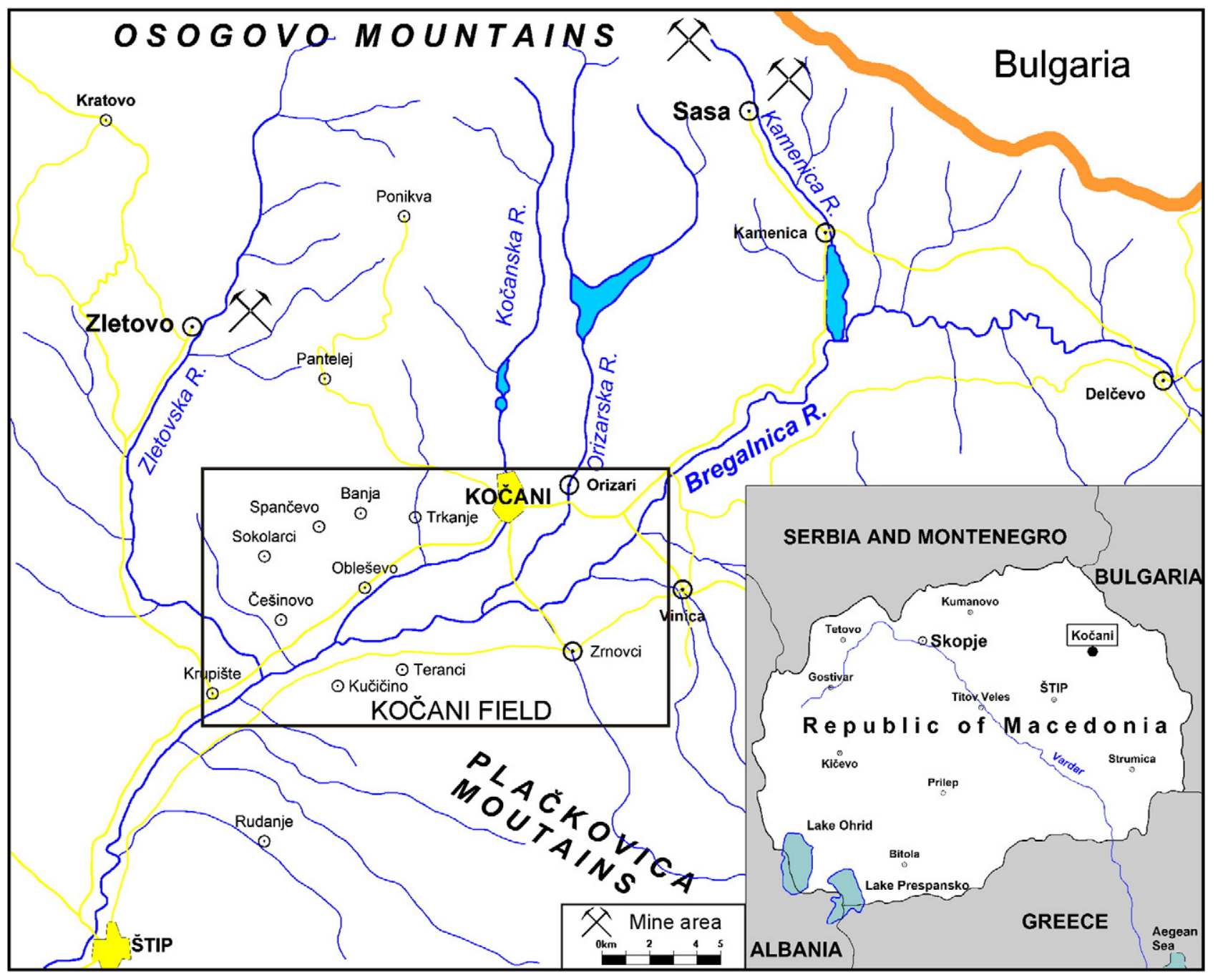

Fig. 1. Study area, Kočani Field. 


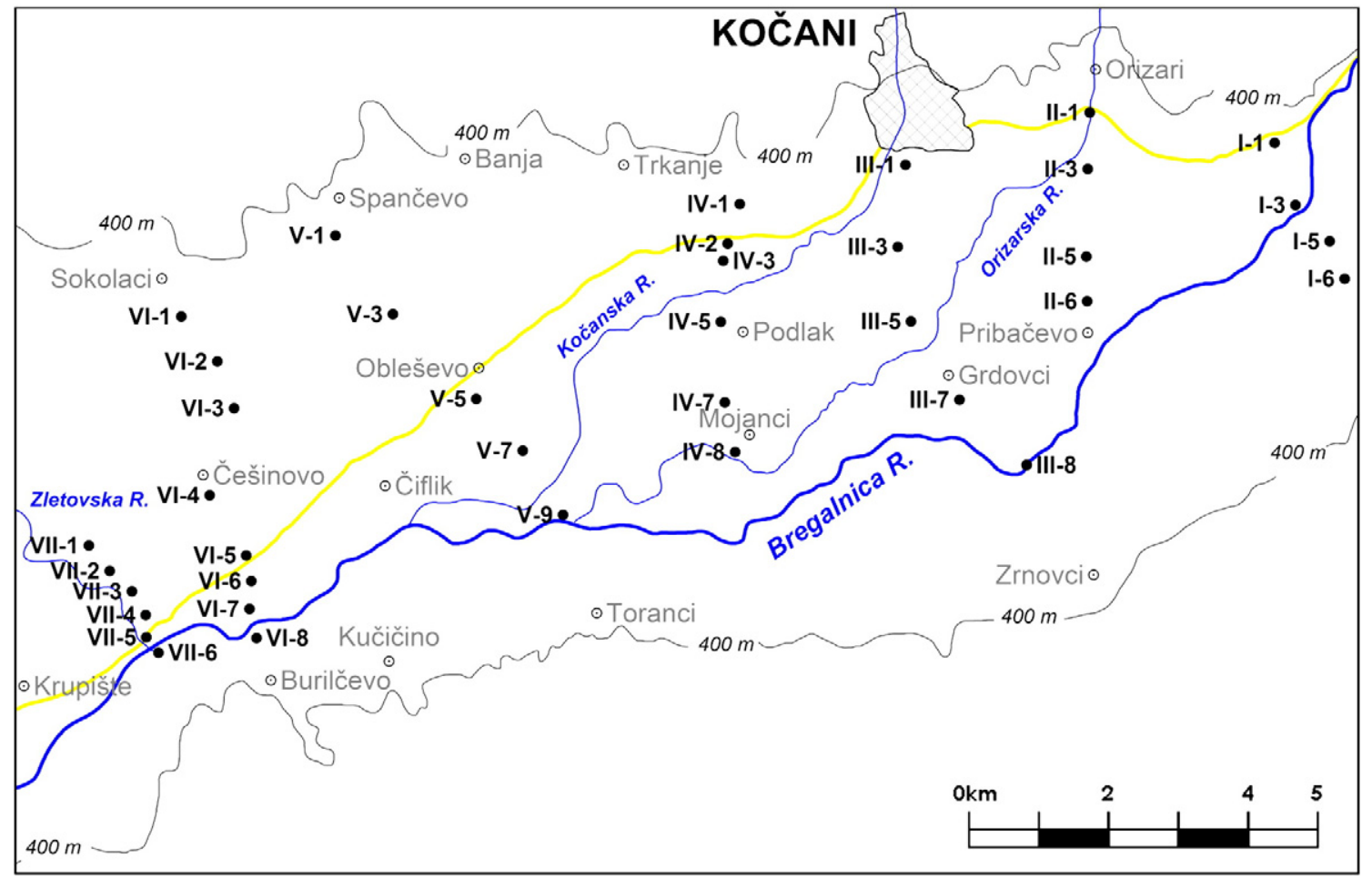

Fig. 2. Map of paddy soil sampling locations.

Near-surface paddy soils were collected from a depth of 0-20 cm because it was impossible to distinguish the $\mathrm{A}, \mathrm{B}$, and $\mathrm{C}$ horizons of the agricultural soil. The paddy soils were sampled using a plastic spade to avoid any metal contamination. Each paddy soil sample comprised a composite of five sub-samples taken within a $1 \times 1 \mathrm{~m}^{2}$.

The paddy soil samples were air dried at $25{ }^{\circ} \mathrm{C}$ for one week and sieved through a $2 \mathrm{~mm}$ polyethylene sieve to remove plant debris, pebbles, and stones. Afterwards, the samples were ground in a mechanical agate grinder into a fine powder for subsequent geochemical analysis.

Physical and chemical soil properties ( $\mathrm{pH}, \mathrm{CEC}$, total organic C, conductivity, and loss on ignition) were determined at the Agricultural Institute of Slovenia (Kmetijski Inštitut Slovenije) following previously established methods.

All paddy soil samples were analysed for REE concentration in a certified commercial Canadian laboratory (Acme Analytical Laboratories, Vancouver, B.C., Canada). REE amounts were determined by inductively coupled plasma mass spectrometry (ICP-MS) after fusion with a mixture of lithium/tetraborate and dissolution in nitric acid.

The accuracy and precision of the paddy soil analyses were assessed using international reference materials such as Canadian Certified Reference Material Project (CCRMP) SO-1 (soil) and United States Geological Survey (USGS) G-1 (granite). The analytical precision and accuracy were better than $\pm 6 \%$ for the REEs, as indicated by the results of duplicate measurements in 10 soil samples as well as duplicate measurements of the G-1 and SO-1 standards.

\subsection{Sequential extraction procedure}

Selected paddy soil samples (I-3, II-6, III-5, VI-4, and VII-2; Fig. 2) were also analysed for the chemical partitioning (binding forms) of REEs by employing a sequential extraction procedure (Li et al., 1995; Tessier et al., 1979).

The paddy soil samples, weighing $1 \mathrm{~g}$, were placed in screw-top test tubes. The precision and accuracy in each batch of 32 samples were monitored by a duplicate pulp split and control sample of WSA (water leach), ESL (Na acetate), OSL (Na pyrophosphate), MSL (weak hydroxylamine), or FSL (strong hydroxylamine). To each sample, $10 \mathrm{ml}$ of leaching solution was added; then, the caps were screwed on, and the tubes were subjected to an extraction procedure.

Solutions were centrifuged, and the clear fluid was decanted into test tubes; the residue was washed with demineralised water, which was decanted and added to the solution for further analysis. A reagent blank was carried in parallel through the leaching and analysis steps.

The sample was leached, centrifuged, decanted, and washed; and then, the residue was leached again in a five-step process from the weakest to the strongest solution: water $\rightarrow$ ammonium acetate $\rightarrow$ sodium pyrophosphate $\rightarrow$ cold hydroxylamine hydrochloride $\rightarrow$ hot hydroxylamine hydrochloride. The procedure and chemical fractions are presented in Table 1.

After the sequential extraction procedure, the concentrations of the analysed elements in the solution were measured using a Perkin Elan 6000 ICP-MS for the determination of over 60 elements.

A QA/QC protocol incorporated a sample duplicate to monitor analytical precision. A reagent blank was used to measure background levels, and an aliquot of in-house reference material was used to monitor accuracy. Raw and final data were verified by a British Columbia Certified Assayer.

Table 1

Sequential extraction procedure, fractions and chemical reagents (Li et al., 1995; Tessier et al., 1979).

\begin{tabular}{|c|c|c|}
\hline Step & Fraction & Chemical reagents \\
\hline 1 & Water soluble & Distilled water \\
\hline 2 & $\begin{array}{l}\text { Exchangeable and } \\
\text { carbonate bound }\end{array}$ & $1 \mathrm{~m}$ ammonium acetate \\
\hline 3 & Organic (oxidisable) & $0.1 \mathrm{~m}$ sodium pyrophosphate \\
\hline 4 & Reducible & Cold $0.1 \mathrm{~m}$ hydroxylamine hydrochloride \\
\hline 5 & Reducible plus residual & Hot $0.25 \mathrm{~m}$ hydroxylamine hydrochloride \\
\hline
\end{tabular}




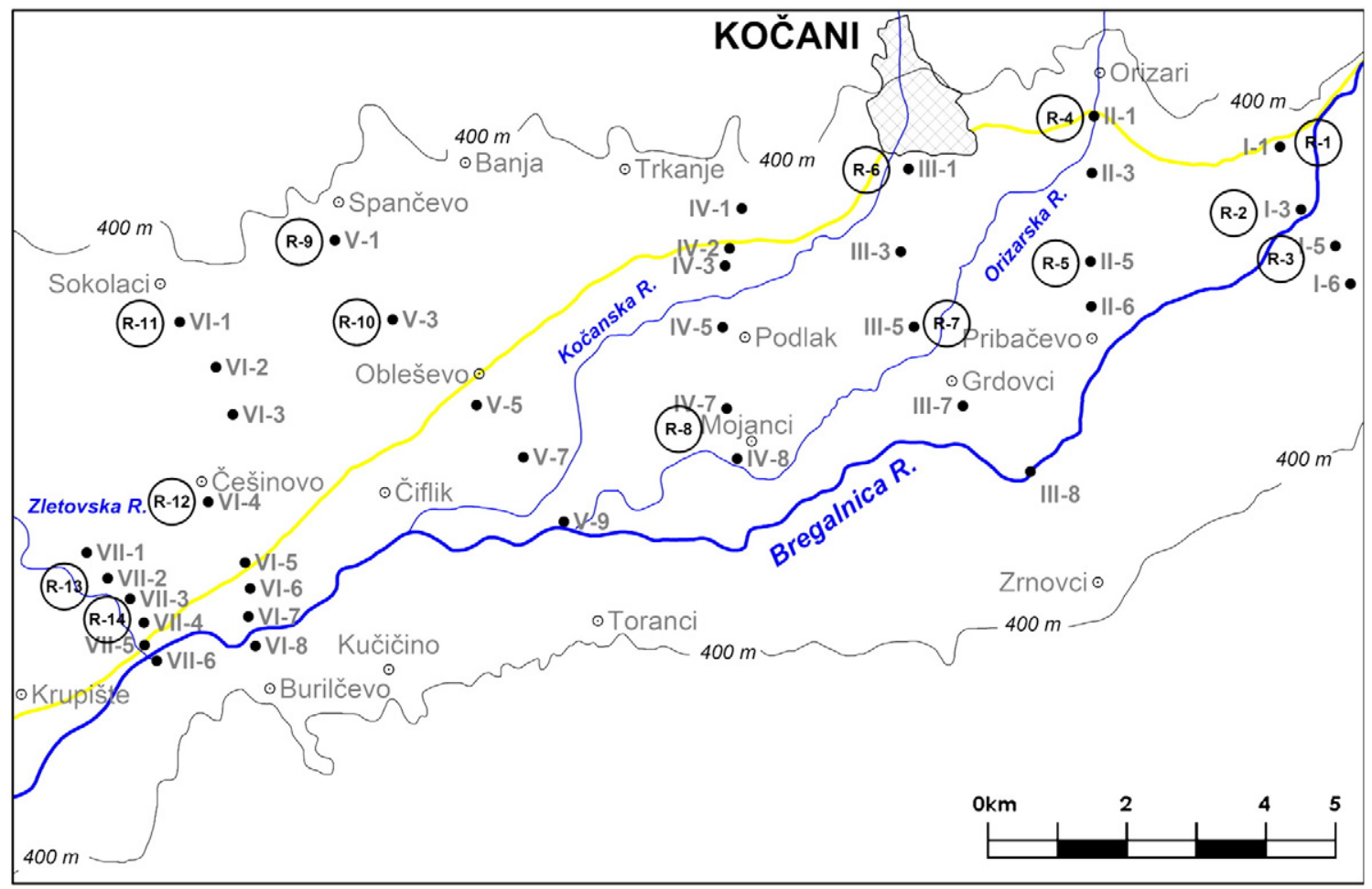

Fig. 3. Map of rice (Oryza sativa L.) sampling locations.

\subsection{Rice sampling and analysis}

Rice grain samples (Oryza sativa L.) with hulls were collected during harvesting in November 2005 from 14 sampling sites across Kočani Field. Selected sampling points were located at the same approximate positions (ranging in area from 0.5 to $1 \mathrm{~m}^{2}$ ) as the corresponding soil sample locations (Fig. 3).

At each sampling site, rice grains were taken from an area of $10 \times 10 \mathrm{~m}^{2}$ to obtain a final composite sample of approximately $1 \mathrm{~kg}$. All samples were stored in polythene bags and were taken to the laboratory for further preparation and treatment.

In the laboratory, the rice samples were washed three times with distilled water to remove soil particles and airborne pollutants and were then oven-dried to a constant weight at $75^{\circ} \mathrm{C}$ for $72 \mathrm{~h}$. The unpolished rice grains without hulls were ground into a fine powder in an agate mortar. The powdered samples were then packed in clean, dry, stoppered glass containers and stored in a refrigerator.

The geochemical analysis of REEs present in the investigated rice samples was carried out in a certified commercial Canadian laboratory (Acme Analytical Laboratories, Ltd). The rice samples were dissolved in environmental-grade nitric acid and then analysed by ICP-MS. Quality control included the analysis of certified reference material (rice flour SRM 1568) from the National Bureau of Standards. The analytical precision and accuracy were better than $\pm 5 \%$ as confirmed by the results of duplicate measurements of three rice samples as well as duplicate measurements of the SRM 1568 standards.

\subsection{Statistical analysis}

To investigate the elemental associations among the analysed elements in the soil and rice, Pearson $R$ correlation analyses were applied to all samples studied. Critical values of the correlation coefficients $(r)$ were as follows: 0.32 at $p \leq 0.05,0.43$ at $p \leq 0.01,0.93$ at $p \leq 0.005$ and 0.91 at $p \leq 0.001$. Results that yielded $p \leq 0.05$ were considered marginally significant, whereas those at $p \leq 0.01$ were deemed significant. Results at $p \leq 0.005$ or $p \leq 0.001$ levels were considered highly significant.
The basic statistical parameters for each element and the statistical calculations mentioned earlier were performed using the statistical software program Statistica VI.

\subsection{Transfer factor (TF) from soil to rice}

Soil-to-plant transfer is one of the key components of human exposure to REEs that seeps into food production. To investigate the transfer values of REEs from soils to crops, the TFs were calculated as follows (Cui et al., 2004):

$\mathrm{TF}=\mathrm{C}_{\text {rice }} / \mathrm{C}_{\text {soil }}$,

where $C_{\text {rice }}$ and $C_{\text {soil }}$ signify REE concentrations in the rice crops and paddy soils, respectively, where the crops are measured on a dry weight basis. In this study, we used the mean concentration values of REEs determined for rice and paddy soil samples.

\section{Results and discussion}

\subsection{Physicochemical characteristics of the paddy soils}

The physicochemical characteristics of the paddy soils studied are given in Table 2.

The overall area was characterised by a weakly acidic soil pH (5.2-6). Soil conductivity was in the range of 6.61 to $51.09 \mathrm{mS} / \mathrm{m}$. CEC values were relatively moderate with an average value of $20.7 \mathrm{mmol} / 100 \mathrm{~g}$.

Table 2

Information about physical and chemical characteristics of the paddy soil samples from Kočani Field.

\begin{tabular}{llll}
\hline & $\mathrm{pH}$ & $\mathrm{CEC}(\mathrm{mmol} / 100 \mathrm{~g})$ & C organic $(\%)$ \\
\hline Range & $5.2-6.0$ & $11.4-38.6$ & $0.70-2.95$ \\
Mean & 5.5 & 20.7 & 1.70 \\
\hline
\end{tabular}


Table 3

Total REE concentrations in the paddy soil of Kočani Field with descriptive statistics, compared to results from: (A) upper continental crust (Taylor and McLennan, 1995); (B) Wedepohl (1995) and (C) Yoshida et al. (1998).

\begin{tabular}{|c|c|c|c|c|c|c|c|c|c|c|c|c|c|c|c|c|}
\hline \multicolumn{2}{|c|}{ Element $\mu \mathrm{g} / \mathrm{g}$} & \multirow[t]{2}{*}{$\mathrm{La}$} & \multirow[t]{2}{*}{$\mathrm{Ce}$} & \multirow[t]{2}{*}{$\operatorname{Pr}$} & \multirow[t]{2}{*}{$\mathrm{Nd}$} & \multirow[t]{2}{*}{$\mathrm{Sm}$} & \multirow[t]{2}{*}{$\mathrm{Eu}$} & \multirow[t]{2}{*}{ Gd } & \multirow[t]{2}{*}{$\mathrm{Tb}$} & \multirow[t]{2}{*}{ Dy } & \multirow[t]{2}{*}{ Ho } & \multirow[t]{2}{*}{$\mathrm{Er}$} & \multirow[t]{2}{*}{$\operatorname{Tm}$} & \multirow[t]{2}{*}{$\mathrm{Yb}$} & \multirow[t]{2}{*}{$\mathrm{Lu}$} & \multirow[t]{2}{*}{ ¿REE } \\
\hline Location & Sample no. & & & & & & & & & & & & & & & \\
\hline $\mathrm{I}-1$ & 1 & 31.6 & 65.4 & 7.6 & 30.1 & 6.0 & 1.14 & 5.80 & 0.98 & 5.93 & 1.16 & 3.44 & 0.53 & 3.32 & 0.51 & 163.51 \\
\hline $\mathrm{I}-3$ & 2 & 48.3 & 99.2 & 11.3 & 45.6 & 8.7 & 1.77 & 7.84 & 1.47 & 7.86 & 1.52 & 4.30 & 0.69 & 4.20 & 0.65 & 243.40 \\
\hline $\mathrm{I}-5$ & 3 & 32.7 & 67.6 & 7.8 & 30.6 & 6.1 & 1.29 & 5.44 & 0.94 & 5.30 & 1.03 & 3.03 & 0.48 & 3.11 & 0.44 & 165.86 \\
\hline $\mathrm{I}-6$ & 4 & 20.9 & 47.0 & 5.3 & 23.7 & 5.3 & 1.29 & 5.09 & 0.93 & 5.21 & 1.10 & 3.16 & 0.50 & 3.02 & 0.49 & 122.99 \\
\hline II-1 & 5 & 39.6 & 84.9 & 9.3 & 39.3 & 7.9 & 1.50 & 6.58 & 1.13 & 5.97 & 1.24 & 3.32 & 0.53 & 3.41 & 0.53 & 205.21 \\
\hline II-3 & 6 & 38.9 & 84.3 & 8.9 & 37.6 & 7.1 & 1.46 & 5.85 & 1.03 & 5.62 & 1.21 & 3.27 & 0.49 & 3.12 & 0.50 & 199.35 \\
\hline II-5 & 7 & 35.3 & 74.9 & 8.4 & 35.7 & 6.7 & 1.31 & 5.21 & 0.98 & 5.05 & 1.13 & 3.04 & 0.49 & 3.05 & 0.46 & 181.72 \\
\hline II-6 & 8 & 38.1 & 83.6 & 9.3 & 40.2 & 7.9 & 1.58 & 6.78 & 1.24 & 6.66 & 1.36 & 3.94 & 0.65 & 4.10 & 0.59 & 206.00 \\
\hline III-1 & 9 & 31.9 & 70.2 & 8.1 & 35.0 & 7.0 & 1.49 & 6.99 & 1.25 & 6.95 & 1.42 & 4.24 & 0.65 & 4.00 & 0.62 & 179.81 \\
\hline III-3 & 10 & 34.9 & 74.1 & 8.5 & 37.2 & 6.9 & 1.46 & 6.76 & 1.17 & 6.52 & 1.33 & 3.80 & 0.57 & 3.78 & 0.59 & 187.58 \\
\hline III-5 & 11 & 49.8 & 103.1 & 11.5 & 45.9 & 8.6 & 1.63 & 7.00 & 1.26 & 6.45 & 1.26 & 3.51 & 0.56 & 3.33 & 0.49 & 244.39 \\
\hline III-7 & 12 & 30.6 & 64.3 & 7.3 & 30.1 & 5.5 & 1.27 & 5.23 & 0.90 & 5.25 & 1.03 & 3.11 & 0.52 & 3.27 & 0.52 & 158.90 \\
\hline III-8 & 13 & 18.4 & 41.2 & 4.8 & 21.0 & 4.3 & 1.00 & 4.04 & 0.67 & 4.28 & 0.83 & 2.45 & 0.40 & 2.64 & 0.39 & 106.40 \\
\hline IV-1 & 14 & 29.7 & 65.7 & 7.6 & 34.3 & 7.0 & 1.91 & 7.44 & 1.22 & 7.13 & 1.40 & 4.16 & 0.63 & 3.90 & 0.58 & 172.67 \\
\hline IV-2 & 15 & 28.3 & 63.6 & 7.4 & 34.1 & 7.0 & 1.77 & 7.34 & 1.23 & 6.84 & 1.39 & 3.95 & 0.60 & 3.60 & 0.57 & 167.69 \\
\hline IV-3 & 16 & 30.2 & 67.3 & 7.9 & 33.6 & 6.7 & 1.73 & 7.23 & 1.28 & 7.34 & 1.35 & 4.02 & 0.60 & 3.68 & 0.56 & 173.49 \\
\hline IV-5 & 17 & 32.3 & 71.0 & 7.6 & 32.3 & 6.1 & 1.31 & 5.63 & 1.01 & 5.91 & 1.06 & 3.28 & 0.51 & 3.29 & 0.50 & 171.80 \\
\hline IV-7 & 18 & 36.5 & 86.7 & 8.7 & 37.1 & 7.0 & 1.37 & 6.34 & 1.08 & 6.12 & 1.11 & 3.48 & 0.51 & 3.37 & 0.54 & 199.92 \\
\hline IV-8 & 19 & 42.0 & 87.0 & 10.1 & 41.6 & 7.4 & 1.43 & 6.78 & 1.10 & 6.28 & 1.19 & 3.45 & 0.52 & 3.37 & 0.51 & 212.73 \\
\hline V-1 & 20 & 39.2 & 79.1 & 8.7 & 35.0 & 6.2 & 1.39 & 4.84 & 0.81 & 4.48 & 0.85 & 2.43 & 0.37 & 2.51 & 0.34 & 186.22 \\
\hline V-3 & 21 & 39.6 & 83.6 & 9.1 & 37.2 & 6.4 & 1.45 & 5.32 & 0.81 & 4.47 & 0.87 & 2.61 & 0.38 & 2.45 & 0.36 & 194.62 \\
\hline V-5 & 22 & 31.6 & 65.8 & 7.3 & 31.0 & 5.8 & 1.26 & 5.46 & 0.95 & 5.25 & 0.98 & 2.92 & 0.47 & 2.98 & 0.44 & 162.21 \\
\hline V-7 & 23 & 26.4 & 56.9 & 6.7 & 28.6 & 5.6 & 1.25 & 5.31 & 0.94 & 5.48 & 1.11 & 3.26 & 0.49 & 3.24 & 0.55 & 145.83 \\
\hline V-9 & 24 & 27.1 & 58.7 & 6.7 & 28.4 & 5.6 & 1.20 & 5.09 & 0.87 & 5.19 & 1.05 & 3.01 & 0.49 & 3.06 & 0.47 & 146.93 \\
\hline VI-1 & 25 & 36.4 & 76.7 & 8.5 & 33.5 & 6.0 & 1.34 & 4.89 & 0.81 & 3.97 & 0.76 & 2.25 & 0.38 & 2.22 & 0.32 & 178.04 \\
\hline VI-2 & 26 & 40.5 & 88.0 & 9.1 & 36.7 & 6.8 & 1.62 & 5.35 & 0.91 & 4.67 & 0.90 & 2.68 & 0.41 & 2.34 & 0.43 & 200.41 \\
\hline VI-3 & 27 & 36.1 & 73.5 & 8.5 & 34.1 & 6.4 & 1.38 & 5.55 & 0.91 & 5.01 & 0.92 & 2.77 & 0.43 & 2.58 & 0.42 & 178.57 \\
\hline VI-4 & 28 & 31.5 & 69.0 & 8.0 & 33.4 & 6.4 & 1.35 & 5.98 & 1.02 & 5.84 & 1.15 & 3.46 & 0.52 & 3.52 & 0.50 & 171.64 \\
\hline VI-5 & 29 & 30.8 & 65.7 & 7.5 & 30.8 & 6.0 & 1.43 & 5.70 & 1.04 & 5.70 & 1.16 & 3.28 & 0.55 & 3.31 & 0.52 & 163.49 \\
\hline VI-6 & 30 & 30.8 & 67.0 & 7.7 & 32.4 & 6.3 & 1.34 & 5.80 & 0.98 & 5.66 & 1.15 & 3.35 & 0.52 & 3.30 & 0.47 & 166.77 \\
\hline VI-7 & 31 & 22.4 & 50.2 & 5.7 & 23.8 & 4.9 & 1.17 & 4.70 & 0.88 & 4.90 & 0.98 & 2.98 & 0.52 & 3.16 & 0.49 & 126.78 \\
\hline VI-8 & 32 & 28.6 & 61.3 & 7.0 & 29.7 & 6.0 & 1.38 & 5.65 & 1.00 & 5.66 & 1.07 & 3.25 & 0.50 & 2.99 & 0.48 & 154.58 \\
\hline VII-1 & 33 & 27.1 & 56.9 & 6.3 & 25.6 & 4.7 & 1.16 & 4.53 & 0.76 & 4.02 & 0.80 & 2.31 & 0.40 & 2.50 & 0.39 & 137.47 \\
\hline VII-2 & 34 & 31.9 & 66.1 & 7.3 & 31.5 & 5.7 & 1.34 & 5.02 & 0.77 & 4.73 & 0.85 & 2.58 & 0.40 & 2.48 & 0.40 & 161.07 \\
\hline VII-3 & 35 & 33.2 & 70.2 & 7.6 & 30.6 & 5.5 & 1.42 & 5.01 & 0.84 & 4.66 & 0.90 & 2.66 & 0.39 & 2.65 & 0.38 & 166.01 \\
\hline VII-4 & 36 & 30.7 & 65.5 & 7.1 & 28.2 & 5.4 & 1.33 & 4.76 & 0.86 & 4.66 & 0.88 & 2.60 & 0.41 & 2.56 & 0.38 & 155.34 \\
\hline VII-5 & 37 & 29.4 & 60.7 & 6.7 & 27.6 & 4.8 & 1.20 & 4.70 & 0.76 & 4.18 & 0.80 & 2.35 & 0.39 & 2.34 & 0.37 & 146.29 \\
\hline \multirow[t]{9}{*}{ VII-6 } & 38 & 35.7 & 75.9 & 8.7 & 36.7 & 6.9 & 1.55 & 6.57 & 1.07 & 6.38 & 1.22 & 3.64 & 0.55 & 3.43 & 0.58 & 188.89 \\
\hline & Mean & 33 & 71 & 7.93 & 33.2 & 6.33 & 1.40 & 5.78 & 1.00 & 5.57 & 1.09 & 3.19 & 0.50 & 3.14 & 0.48 & 173.54 \\
\hline & Median & 32 & 68 & 7.71 & 33.5 & 6.25 & 1.38 & 5.59 & 0.98 & 5.55 & 1.11 & 3.26 & 0.51 & 3.20 & 0.49 & 171.72 \\
\hline & Min. & 18 & 41 & 4.75 & 21.0 & 4.30 & 1.00 & 4.04 & 0.67 & 3.97 & 0.76 & 2.25 & 0.37 & 2.22 & 0.32 & 106.40 \\
\hline & Max. & 50 & 103 & 11.50 & 45.9 & 8.70 & 1.91 & 7.84 & 1.47 & 7.86 & 1.52 & 4.30 & 0.69 & 4.20 & 0.65 & 244.39 \\
\hline & S.D. & 7 & 13 & 1.40 & 5.5 & 1.00 & 0.19 & 0.94 & 0.18 & 0.97 & 0.20 & 0.56 & 0.08 & 0.52 & 0.08 & 29.01 \\
\hline & A & 30 & 64 & 7.1 & 26 & 4.5 & 0.88 & 3.8 & 0.64 & 3.5 & 0.8 & 2.3 & 0.33 & 2.2 & 0.32 & \\
\hline & B & 32.3 & 65.7 & 6.3 & 25.9 & 4.7 & 0.95 & 2.8 & 0.5 & 2.9 & 0.62 & / & / & 1.5 & 0.27 & \\
\hline & $\mathrm{C}$ & 18.0 & 40 & 4.5 & 18.0 & 3.7 & 0.96 & 3.7 & 0.56 & 3.3 & 0.68 & 2.0 & 0.29 & 2.0 & 0.39 & \\
\hline
\end{tabular}

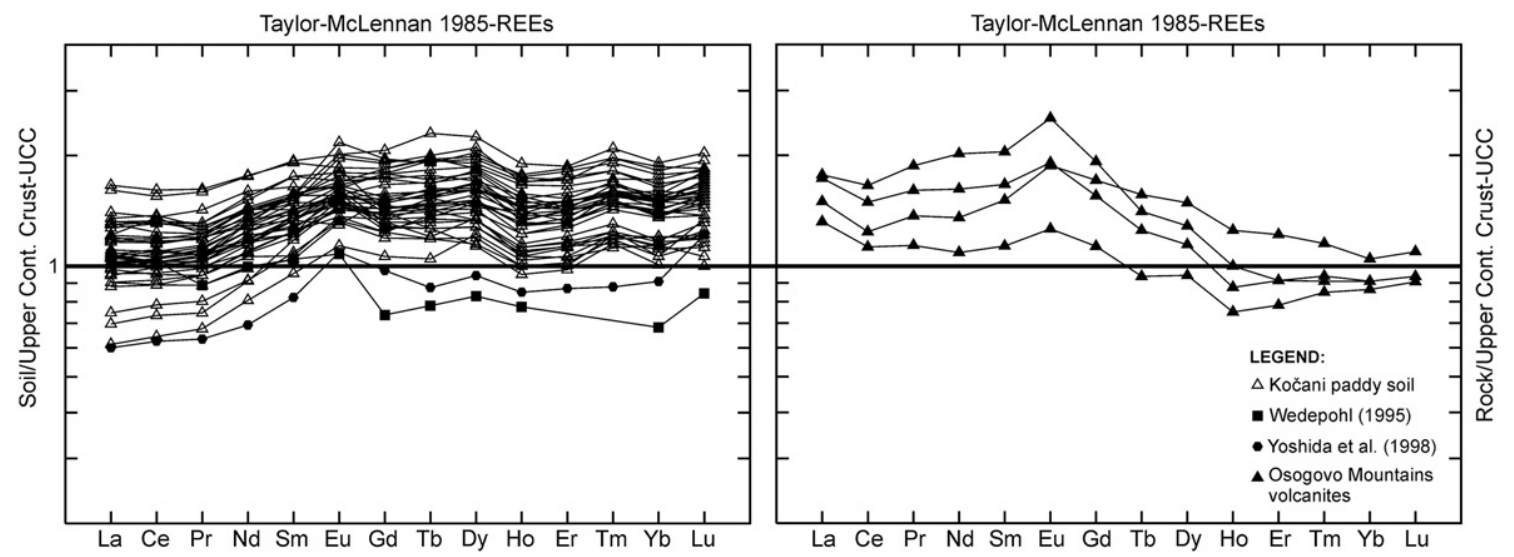

Fig. 4. REE patterns normalised to the upper continental crust (Taylor and McLennan, 1995) for the paddy soil of the Kočani Field and volcanites from the Osogovo Mountains. The REE content of the volcanites is taken from Serafimovski et al. (2005). 
Table 4

Pearson's correlations between REE concentrations in paddy soil samples (marked correlations are significant at $p<0.05$ ).

\begin{tabular}{|c|c|c|c|c|c|c|c|c|c|c|c|c|c|c|}
\hline & La & $\mathrm{Ce}$ & $\operatorname{Pr}$ & $\mathrm{Nd}$ & $\mathrm{Sm}$ & $\mathrm{Eu}$ & Gd & $\mathrm{Tb}$ & Dy & Ho & $\mathrm{Er}$ & $\mathrm{Tm}$ & $\mathrm{Yb}$ & $\mathrm{Lu}$ \\
\hline $\mathrm{La}$ & 1.00 & 0.98 & 0.98 & 0.93 & 0.82 & 0.53 & 0.49 & 0.46 & 0.31 & 0.27 & 0.21 & 0.17 & 0.16 & 0.13 \\
\hline $\mathrm{Ce}$ & 0.98 & $\overline{1.00}$ & $\overline{0.98}$ & $\overline{0.95}$ & $\overline{0.86}$ & $\overline{0.58}$ & $\overline{0.55}$ & $\overline{0.52}$ & 0.37 & 0.33 & 0.29 & 0.23 & 0.23 & 0.20 \\
\hline $\operatorname{Pr}$ & $\overline{0.98}$ & 0.98 & $\overline{1.00}$ & $\overline{0.98}$ & $\overline{0.90}$ & $\overline{0.61}$ & $\overline{0.63}$ & $\overline{0.60}$ & 0.47 & $\overline{0.43}$ & 0.38 & 0.33 & 0.32 & 0.28 \\
\hline $\mathrm{Nd}$ & $\overline{0.93}$ & $\overline{0.95}$ & 0.98 & $\overline{1.00}$ & $\overline{0.95}$ & 0.70 & $\overline{0.74}$ & $\overline{0.70}$ & 0.58 & 0.55 & $\overline{0.50}$ & $\overline{0.45}$ & $\overline{0.44}$ & 0.41 \\
\hline $\mathrm{Sm}$ & $\overline{\mathbf{0 . 8 2}}$ & $\overline{0.86}$ & $\overline{0.90}$ & 0.95 & $\overline{1.00}$ & $\overline{\mathbf{0 . 7 7}}$ & $\overline{\mathbf{0 . 8 5}}$ & $\overline{0.84}$ & $\overline{0.74}$ & $\overline{0.74}$ & $\overline{\mathbf{0 . 6 8}}$ & $\overline{0.64}$ & $\overline{\mathbf{0 . 6 2}}$ & $\overline{0.59}$ \\
\hline $\mathrm{Eu}$ & $\overline{0.53}$ & $\overline{0.58}$ & $\overline{0.61}$ & $\overline{\mathbf{0 . 7 0}}$ & $\mathbf{0 . 7 7}$ & $\overline{1.00}$ & $\overline{0.83}$ & $\overline{\mathbf{0 . 7 7}}$ & $\overline{\mathbf{0 . 7 1}}$ & $\overline{0.67}$ & $\overline{0.66}$ & $\overline{\mathbf{0 . 5 9}}$ & $\overline{0.52}$ & $\overline{0.52}$ \\
\hline $\mathrm{Gd}$ & $\overline{0.49}$ & 0.55 & $\overline{0.63}$ & $\overline{0.74}$ & $\overline{0.85}$ & 0.83 & $\overline{1.00}$ & $\overline{0.96}$ & 0.95 & $\overline{0.91}$ & $\overline{0.91}$ & $\overline{0.86}$ & $\overline{0.84}$ & $\overline{0.82}$ \\
\hline $\mathrm{Tb}$ & $\overline{0.46}$ & $\overline{0.52}$ & $\overline{0.60}$ & $\overline{\mathbf{0 . 7 0}}$ & $\overline{0.84}$ & $\overline{0.77}$ & 0.96 & $\overline{1.00}$ & $\overline{0.96}$ & $\overline{0.95}$ & $\overline{0.94}$ & $\overline{0.92}$ & $\overline{0.89}$ & $\overline{0.86}$ \\
\hline Dy & $\overline{0.31}$ & 0.37 & $\overline{0.47}$ & $\overline{\mathbf{0 . 5 8}}$ & $\overline{0.74}$ & $\overline{\mathbf{0 . 7 1}}$ & $\overline{0.95}$ & 0.96 & $\overline{1.00}$ & $\overline{0.96}$ & $\overline{0.98}$ & $\overline{0.94}$ & $\overline{0.93}$ & $\overline{0.92}$ \\
\hline Ho & 0.27 & $\overline{0.33}$ & $\overline{0.43}$ & $\overline{0.55}$ & $\overline{0.74}$ & $\overline{0.67}$ & $\overline{0.91}$ & $\overline{0.95}$ & 0.96 & $\overline{1.00}$ & $\overline{0.98}$ & $\overline{0.96}$ & $\overline{0.95}$ & $\overline{0.93}$ \\
\hline $\mathrm{Er}$ & 0.21 & $\overline{0.29}$ & $\overline{0.38}$ & $\overline{0.50}$ & $\overline{0.68}$ & $\overline{0.66}$ & $\overline{0.91}$ & $\overline{0.94}$ & $\overline{0.98}$ & 0.98 & $\overline{1.00}$ & 0.97 & $\overline{0.96}$ & 0.95 \\
\hline $\mathrm{Tm}$ & 0.17 & 0.23 & $\overline{0.33}$ & 0.45 & $\overline{0.64}$ & $\overline{0.59}$ & 0.86 & 0.92 & $\overline{0.94}$ & $\overline{0.96}$ & 0.97 & 1.00 & $\overline{0.97}$ & 0.95 \\
\hline $\mathrm{Yb}$ & 0.16 & 0.23 & $\overline{0.32}$ & $\overline{0.44}$ & $\overline{0.62}$ & $\overline{0.52}$ & $\overline{0.84}$ & $\overline{0.89}$ & $\overline{0.93}$ & $\overline{0.95}$ & $\overline{0.96}$ & 0.97 & $\overline{1.00}$ & 0.95 \\
\hline $\mathrm{Lu}$ & 0.13 & 0.20 & $\overline{0.28}$ & $\overline{0.41}$ & $\overline{0.59}$ & $\overline{0.52}$ & $\overline{0.82}$ & $\overline{\mathbf{0 . 8 6}}$ & $\overline{0.92}$ & $\overline{0.93}$ & $\overline{0.95}$ & $\overline{\mathbf{0 . 9 5}}$ & 0.95 & $\overline{1.00}$ \\
\hline
\end{tabular}

\subsection{REEs in the paddy soils}

The concentrations of REEs in the paddy soils from Kočani Field are presented in Table 3. For comparison, they are presented alongside the concentrations of REEs in the upper continental crust (Taylor and McLennan, 1995; Wedepohl, 1995) and the mean concentrations of the lanthanides in soils reported by Yoshida et al. (1998). A summary of the main statistical parameters (mean, median, range, and SD) was added, as well.

The concentration of REEs in the paddy soil samples detected during this study ranged from 106.4 to $244.4 \mu \mathrm{g} / \mathrm{g}$ with a mean value of $173.5 \mu \mathrm{g} / \mathrm{g}$. Thus, the mean REE levels in the paddy soil were slightly
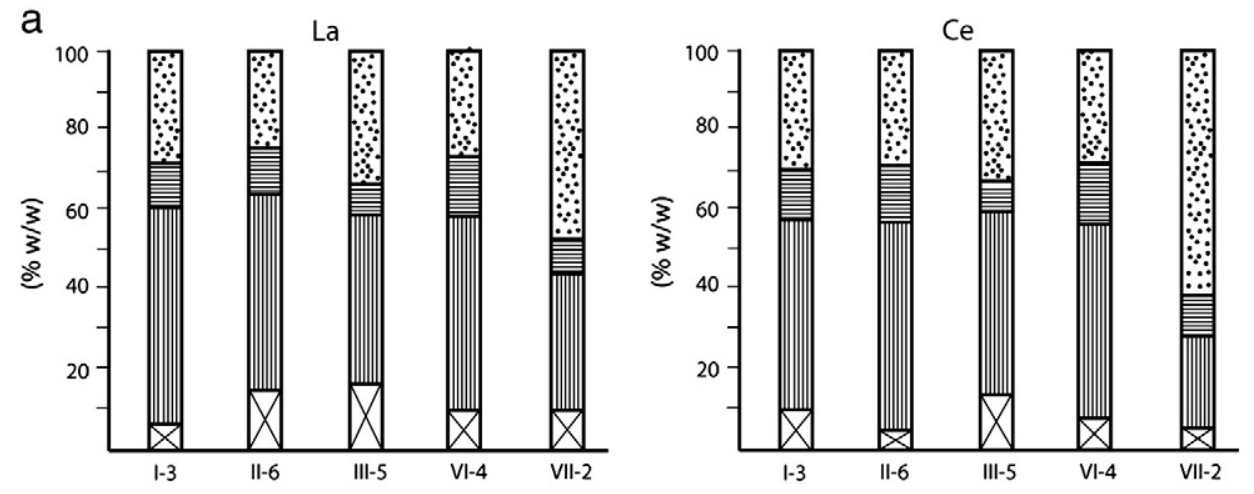

$\operatorname{Pr}$
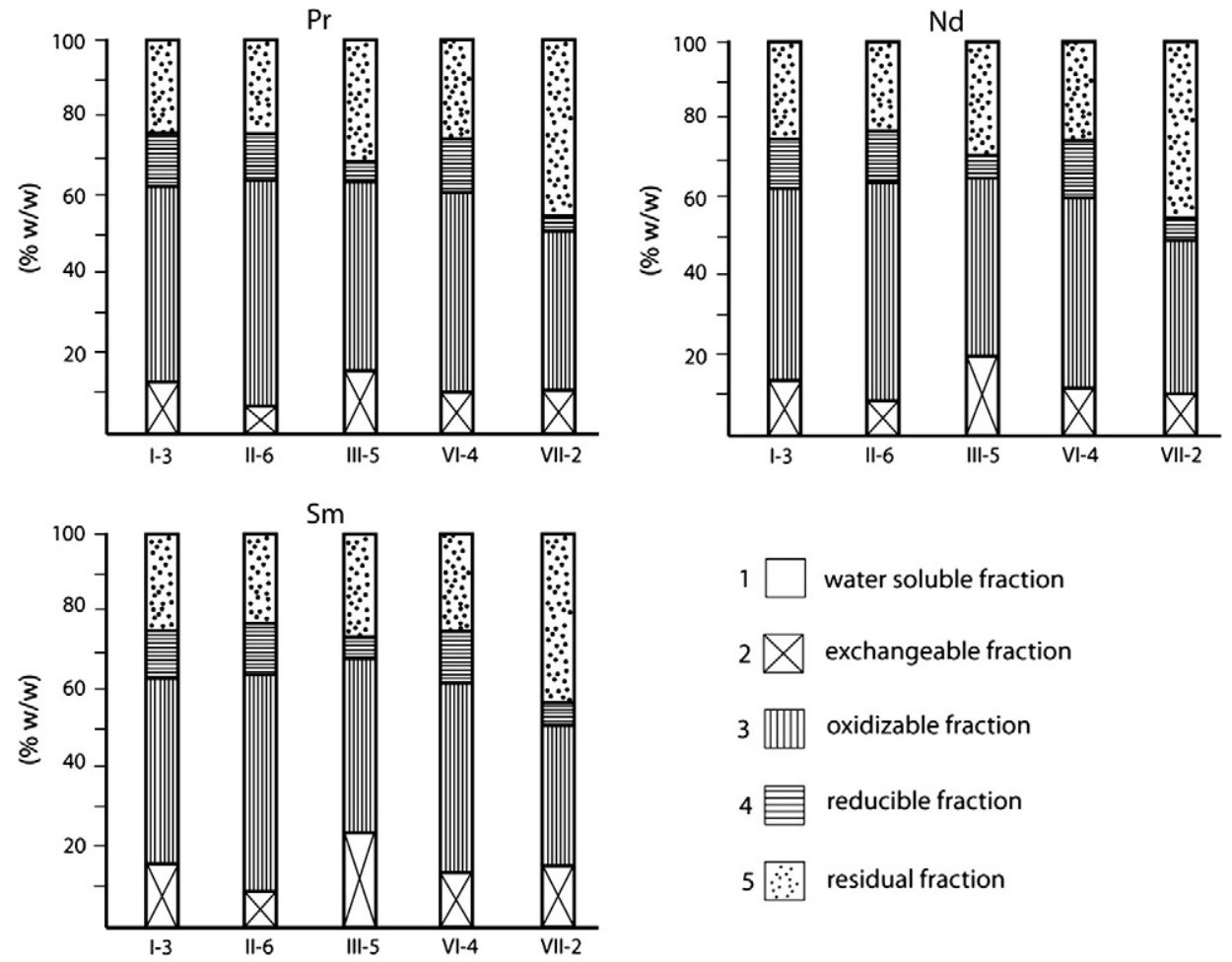

Fig. 5. $a$ and $b$. The results of the sequential extraction procedure (REE binding forms). 
N.R. Šmuc et al. / Geoderma 183-184 (2012) 1-11
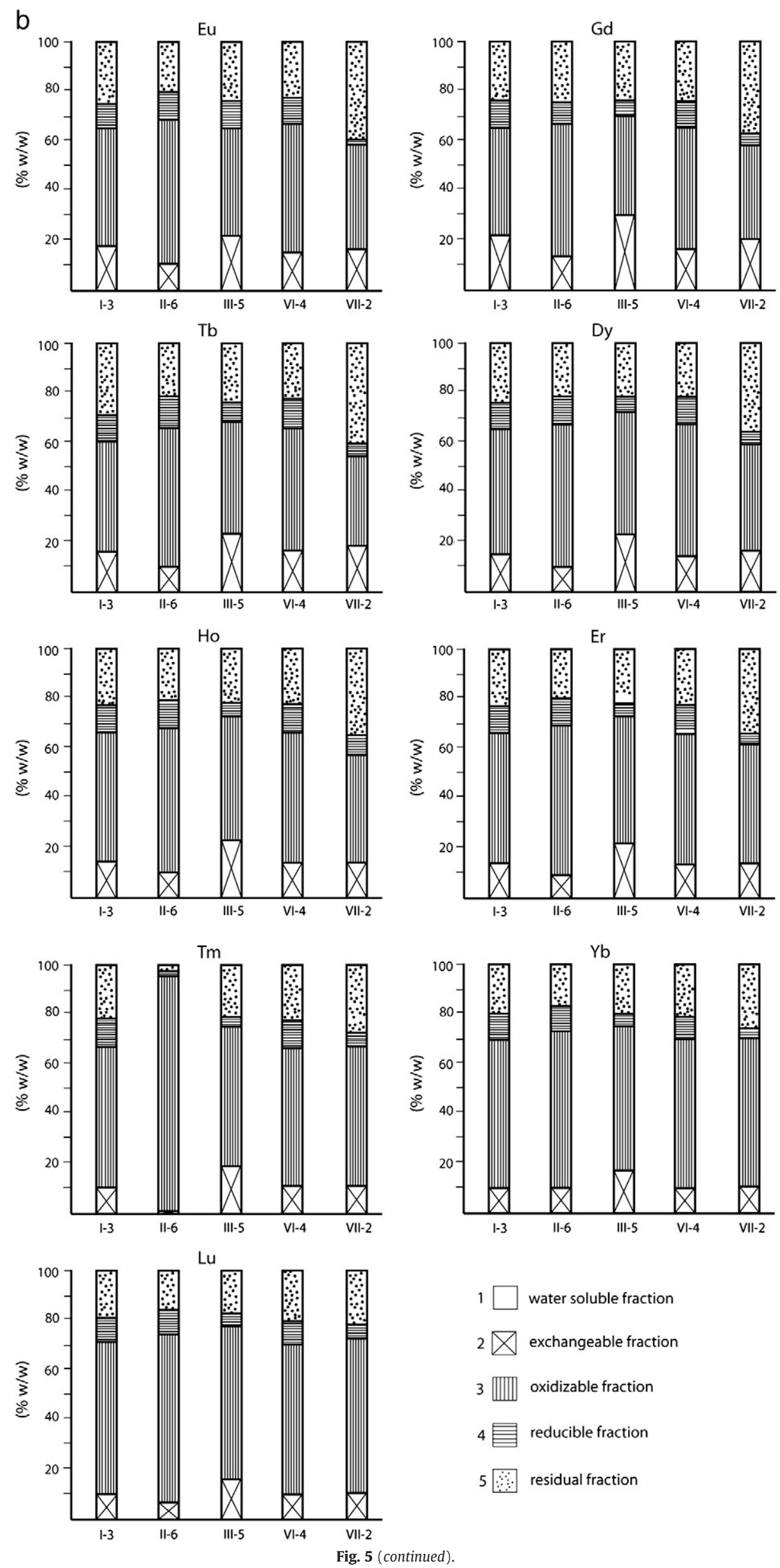
higher than the measured mean concentrations of REE in the average upper continental crust (Taylor and McLennan, 1995; Wedepohl, 1995) and in the mean concentrations of the lanthanides in soils (Yoshida et al., 1998). LREEs (La-Sm) accounted for $87 \%$ of the total REE content in the investigated paddy soils, which is in agreement with the report of Tyler (2004), indicating that LREEs are usually more abundant in soils than HREEs, just as they are in the earth's crust.

Because of the low solubility and relative immobility of REEs in the upper crust, the REE composition of soils is inherited from parent rocks (Ross et al., 1995). Basically, the concentration of individual REEs in a paddy soil depends on the parent material and soil formation factors (Hu et al., 2006; Zhu and Liu, 1988). The paddy soils from Kočani Field originate from the predominantly acidic and intermediate igneous and metamorphic lithologies (different variations of granites, diabases, gabbros and schists) (Serafimovski and Aleksandrov, 1995) exposed in the drainage system of the Bregalnica and Zletovska Rivers, as well as in the surroundings of the investigated area. Soils derived from granitic and metamorphic rocks tend to have higher REE concentrations (Hu et al., 2006; Ure and Bacon, 1979). Granitic rocks usually include higher amounts of LREEs compared with other igneous rocks such as basalts and andesites (Herman, 1970; Reiman and Caritat, 1998). In addition, among the essential minerals, salic minerals preferentially concentrate LREEs, and femic minerals concentrate HREEs.

The upper continental crust normalised patterns of the Kočani paddy soil did not differ appreciably and revealed a similar REE pattern of Kočani soils to REE concentrations in the average upper continental crust (Wedepohl, 1995) and in soils (Yoshida et al., 1998) (Fig. 4) as well as a positive Eu anomaly. The REE normalised patterns (Fig. 4) of the Kočani paddy soil and selected volcanites from the Osogovo Mountains are characterised by similar concentrations of LREEs, a higher HREE content relative to the original material of the soil, in addition to a prominent Eu anomaly.

The elevated HREE concentrations in the paddy soil samples can be explained by the contribution of mafic and ultramafic rocks to soil formation (Hu et al., 2006). The mafic and ultramafic rocks (different variations of gabbros) are also located around the Kočani Field area (Serafimovski and Aleksandrov, 1995). The preferential decomposition of femic minerals and calcic plagioclases compared with the more resistant sodic and potassium feldspars during the weathering (Laveuf and Cornu, 2009) of the exposed lithologies in the drainage area of the Bregalnica River and its tributaries could result in an enrichment of HREEs in the paddy soil. Amphiboles and pyroxenes present in the Kočani paddy soil can be considered to be another source of HREE enrichment (Dolenec et al., 2007; Laveuf and Cornu, 2009).

The correlation analysis (Table 4) between REEs in paddy soil samples showed (1) highly significant correlations between elements from the LREE group and (2) highly significant correlations between HREEs. These findings confirm the aforementioned results and provide evidence for similar input sources and common geochemical characteristics of the elements.

Additionally, the REE content of the paddy soil is affected - and thus enriched - by different anthropogenic inputs such as manure, phosphate fertilisers, and different waste effluents (Brown et al., 1990; Protano and Riccobono, 2002; Tsumura and Yamasaki, 1993; Wang et al., 2004; Yoshida et al., 1998; Yuan et al., 2001).

Kočani Field is located within a province that has long been used for mining ( $\mathrm{Pb}-\mathrm{Zn}$ Zletovo Kratovo and $\mathrm{Pb}-\mathrm{Zn}$ Sasa Toranica) and agriculture. The Kočani paddy soil is irrigated with water from the Zletovska and Bregalnica Rivers, which both contain acid mine drainage and untreated effluent from the Zletovo-Kratovo and Sasa-Toranica ore districts. It has been established that the paddy soil of Kočani Field has been polluted with several heavy metals (Dolenec et al., 2007; Rogan Šmuc, 2010; Rogan et al., 2009). Unfortunately, a study about REE concentrations in riverine waters has not yet been finalised, and information about phosphate fertiliser application practices is not currently available.
Consequently, we suppose that the detected concentrations of REEs in Kočani paddy soils are associated with the concentrations of these elements in the predominantly acidic and intermediate igneous rocks that are a main source material for the paddy soils of Kočani Field (Dolenec et al., 2007; Serafimovski and Aleksandrov, 1995). Possible anthropogenic inputs to soil REE level will be evaluated in a future study.

\subsection{REE mobility and bioavailability results from paddy soil samples}

Fig. 5 and $\mathrm{b}$ shows the results of the sequential extraction procedure (REE binding forms).

The water-soluble fraction (1) includes easily soluble REE species, which are highly mobile and potentially bioavailable in the environment. The leaching of REEs in this fraction represents a major environmental concern (Filgueiras et al., 2002).

The exchangeable fraction (2) contains weakly (electrostatically) bound REE species, which can be released through ion exchange processes, and REEs that are precipitated with carbonates. Changes in ionic composition, influencing adsorption-desorption reactions or lowering the $\mathrm{pH}$, could cause the remobilisation of REEs from this fraction. REEs in the exchangeable fraction are the most readily available for plant uptake and are therefore very labile (Filgueiras et al., 2002).

The oxidisable fraction (3) corresponds to elements occurring as oxidisable minerals and organically bound REEs. Under oxidising conditions, this fraction releases REEs that are linked to organic matter within the soil matrix into solution (Filgueiras et al., 2002).

The reducible fraction (4) comprises unstable REE forms connected to amorphous Mn hydroxides. The REEs bind strongly to these hydroxides, which are very thermodynamically unstable under reducing conditions (Filgueiras et al., 2002). In the reducible + residual fraction (5), REEs are linked to the reducible part of amorphous Fe hydroxides and, under reducing conditions, are expected to be released in nature. The residual fraction contains naturally occurring crystalline Mn hydroxide minerals, which can hold REEs within their crystalline matrix. REEs in residuals are unlikely to be discharged under normal environmental conditions. Therefore, the REEs associated with this fraction can only be released as a result of weathering (Dean, 2007; Filgueiras et al., 2002; Fuentes et al., 2004; Kazi et al., 2002).

Middle to heavy REEs ( $\mathrm{Sm}$ to $\mathrm{Yb}$ ) are known to be preferentially extracted compared with LREEs (Aubert et al., 2004), and this phenomenon was confirmed through our study that showed extraction percentages of $48 \%$ for HREEs and of $35 \%$ for LREEs.

In all paddy soil samples studied, REEs were predominantly associated with the oxidisable fraction (3) (Fig. 5a and b), which is in agreement with the results of Li et al. (1998).

The second most important fraction was the reducible + residual one (5) (Fig. 5a and b). A minority of REEs were connected with the water-soluble (1), reducible (4) and exchangeable fractions (2) (Fig. 5a and b). Zhu and Xing (1992) and Wang et al. (1998) found similar results in their studies.

The studied fractions can be ranked from highest to lowest percentage of REEs as follows (Fig. 5a and b): oxidisable fraction (3) $>$ reducible + residual fraction $(5)>$ exchangeable fraction (2) $>$ reducible fraction (4) > water-soluble fraction (1).

The mobility and bioavailability characteristics of REEs in the soils are closely related to their types of binding forms.

REEs fixed in organic matter as chelates or organic sulphides are released only under strongly oxidising conditions. REEs bound in a reducible form (Fe-Mn hydroxides) are also not fully available to plants. Only after changing environmental conditions, such as in a reducing wetland environment, might REEs be released. The residual forms of REEs are fixed in the lattices of minerals and are not available to surrounding ecosystems (Hu et al., 2006). REEs present in the 
water-soluble (1) and exchangeable (2) fractions are readily available for plant uptake and are thereby very labile (Filgueiras et al., 2002).

Rice cultivation in paddy fields generally requires moderate flooding. In our research, REEs are mostly bound to the oxidisable fraction and can consequently be released into surrounding ecosystems under oxidising conditions in a paddy field.

Very small percentages of REEs exist in the water-soluble and exchangeable fractions (Fig. 5a and b), signifying the low mobility capacity of REEs in the paddy soils of Kočani Field.

\subsection{REEs in rice grains}

REE concentrations and their main statistical parameters (mean, median, range and SD) of unpolished rice samples from Kočani Field are introduced in Table 5. The concentrations of lanthanides in plants decrease with increasing atomic number (Kabata-Pendias and Pendias, 2001). The contents of $\mathrm{Eu}, \mathrm{Gd}, \mathrm{Tb}, \mathrm{Ho}, \mathrm{Er}, \mathrm{Tm}, \mathrm{Yb}$, and Lu were below the detection limit of the ICP-MS and were not considered in this study.

The concentrations of REEs in plants vary within a broad range from below 0.001 to above $15 \mu \mathrm{g} / \mathrm{g}$ (Kabata-Pendias and Pendias, 2001). The sum total of the REEs in unpolished rice grain samples from Kočani Field range from 0.037 to $0.155 \mu \mathrm{g} / \mathrm{g}$ with a mean value of $0.074 \mu \mathrm{g} / \mathrm{g}$ (Table 5).

Pearson's correlation coefficients between REEs in rice samples are displayed in Table 6. A highly significant correlation exists between all REEs detected in rice samples, indicating their common geochemical characteristics (Hu et al., 2006; Li et al., 1998).

A higher bioavailability of REEs leads to a higher uptake of REEs by plants. The mobility and bioavailability characteristics of REEs in soils are closely related to the water-soluble and exchangeable fractions of REEs as well as to other physicochemical soil properties such as $\mathrm{pH}$, CEC, and clay content (Kabata-Pendias and Pendias, 2001). We found small percentages of REEs in the water-soluble and exchangeable fractions, indicating the weak mobility and bioavailability of REEs in the paddy soils of Kočani Field. Consequently, the concentrations of REEs determined in rice grain samples were quite low.

The concentration of REEs in plants is extremely variable and dependent on the plant species and its corresponding habitat (Ichihashi et al., 1992; Laveuf and Cornu, 2009; Li et al., 1998; Tyler, 2004; Wyttenbach et al., 1998). Different parts of a plant can be ranked in the following order based on their REE content: root $>$ leaf $>$ stem > grain ( Li et al., 1998; Xu et al., 2002). The REE concentrations in roots are usually considerably higher than the REE concentrations in other plant parts ( $\mathrm{Li}$ et

Table 5

Total REE ( $\mathrm{La}-\mathrm{Sm}$ ) concentrations in the unpolished rice of Kočani Field and corresponding basic descriptive statistics.

\begin{tabular}{llllllll}
\hline \multicolumn{2}{l}{$\begin{array}{l}\text { Elements }(\mu \mathrm{g} / \mathrm{g}) / \\
\text { sample ID }\end{array}$} & La & Ce & Pr & Nd & Sm & REE \\
\hline I-1 & R-1 & 0.014 & 0.029 & 0.004 & 0.012 & 0.002 & 0.060 \\
I-3 & R-2 & 0.014 & 0.033 & 0.004 & 0.011 & 0.002 & 0.064 \\
I-5 & R-3 & 0.016 & 0.033 & 0.004 & 0.013 & 0.003 & 0.068 \\
II-1 & R-4 & 0.026 & 0.055 & 0.006 & 0.024 & 0.005 & 0.114 \\
II-5 & R-5 & 0.013 & 0.027 & 0.003 & 0.011 & 0.003 & 0.057 \\
III-1 & R-6 & 0.012 & 0.024 & 0.003 & 0.009 & 0.002 & 0.050 \\
III-5 & R-7 & 0.017 & 0.038 & 0.004 & 0.015 & 0.004 & 0.079 \\
IV-7 & R-8 & 0.012 & 0.027 & 0.003 & 0.011 & 0.002 & 0.055 \\
V-1 & R-9 & 0.015 & 0.033 & 0.003 & 0.014 & 0.003 & 0.068 \\
V-3 & R-10 & 0.009 & 0.017 & 0.002 & 0.008 & 0.002 & 0.037 \\
VI-1 & R-11 & 0.035 & 0.078 & 0.008 & 0.029 & 0.006 & 0.155 \\
VI-4 & R-12 & 0.016 & 0.033 & 0.004 & 0.014 & 0.003 & 0.069 \\
VII-2 & R-13 & 0.009 & 0.019 & 0.003 & 0.008 & 0.002 & 0.041 \\
VII-4 & R-14 & 0.026 & 0.059 & 0.006 & 0.023 & 0.006 & 0.120 \\
Statistics & Mean & 0.027 & 0.036 & 0.004 & 0.014 & 0.003 & 0.074 \\
& Median & 0.014 & 0.033 & 0.004 & 0.012 & 0.002 & 0.066 \\
& Minimum & 0.009 & 0.017 & 0.002 & 0.008 & 0.002 & 0.037 \\
& Maximum & 0.035 & 0.078 & 0.008 & 0.029 & 0.006 & 0.155 \\
& Std. dev. & 0.007 & 0.017 & 0.002 & 0.006 & 0.001 & 0.033 \\
\hline
\end{tabular}

Table 6

Pearson's correlation coefficients between REEs in rice samples (marked correlations are significant at $p<0.05$ ).

\begin{tabular}{|c|c|c|c|c|c|}
\hline & La & $\mathrm{Ce}$ & $\operatorname{Pr}$ & $\mathrm{Nd}$ & $\mathrm{Sm}$ \\
\hline $\mathrm{La}$ & 1.00 & 1.00 & 0.99 & 0.99 & 0.95 \\
\hline $\mathrm{Ce}$ & 1.00 & $\overline{1.00}$ & $\overline{0.99}$ & $\overline{0.99}$ & $\overline{0.95}$ \\
\hline $\mathrm{Pr}$ & $\overline{0.99}$ & 0.99 & $\overline{1.00}$ & $\overline{0.98}$ & $\overline{0.94}$ \\
\hline $\mathrm{Nd}$ & $\overline{0.99}$ & $\overline{0.99}$ & 0.98 & $\overline{1.00}$ & $\overline{0.97}$ \\
\hline $\mathrm{Sm}$ & $\overline{0.95}$ & $\overline{0.95}$ & $\overline{0.94}$ & 0.97 & $\overline{1.00}$ \\
\hline
\end{tabular}

al., 1998). Thus, REEs can be accumulated and retained by the roots of rice, with only small portions of the REEs reaching other parts of the plant (Li et al., 1998). This fact helps explain why the concentrations of REEs in rice grain samples from Kočani Field were very low.

\subsection{Transfer factor (TF) values for rice}

Table 7 lists the TF values for $\mathrm{La}, \mathrm{Ce}, \mathrm{Pr}, \mathrm{Nd}$, and $\mathrm{Sm}$ as well as the main statistical parameters for the TF values (mean, median, range and SD).

The TF values for REEs in rice were generally very low (Table 7), and they confirmed the weak accumulation of REEs ( $\mathrm{La}, \mathrm{Ce}, \mathrm{Pr}, \mathrm{Nd}$, and $\mathrm{Sm}$ ) by crops.

The mean values of TF calculations for $\mathrm{La}, \mathrm{Ce}, \mathrm{Pr}, \mathrm{Nd}$, and Sm were very similar: $4.61 \times 10^{-4}(\mathrm{La}), 4.71 \times 10^{-4}(\mathrm{Ce}), 4.69 \times 10^{-4}(\mathrm{Pr})$, $4.16 \times 10^{-4}(\mathrm{Nd})$, and $4.7 \times 10^{-4}(\mathrm{Sm})$. Such values may indicate similar fractionation events of these elements in the paddy soil-rice system of Kočani Field. Alternatively, the upper continental crust normalised pattern for La-Sm in soils and the normalised pattern for La-Sm in soil/ rice revealed deviations between Pr (higher) and Nd (lower) values, suggesting different fractionation events between these elements in the soil/plant system (Fig. 6).

The total concentrations of La, Ce, Pr, Nd, and Sm in the paddy soil samples were correlated with total $\mathrm{La}, \mathrm{Ce}, \mathrm{Pr}, \mathrm{Nd}$, and Sm concentrations in the rice grain samples (Table 8). No relationship between the total content of $\mathrm{La}, \mathrm{Ce}, \mathrm{Pr}, \mathrm{Nd}$, and $\mathrm{Sm}$ in soils and $\mathrm{La}, \mathrm{Ce}, \mathrm{Pr}, \mathrm{Nd}$, and $\mathrm{Sm}$ in rice grains was obtained. This finding is in agreement with other studies reporting that the total content of REEs in soils could not predict plant REE uptake and that the concentrations of individual REEs were not a function of their total content in soils (Laveuf and Cornu, 2009; Li et al., 1998; Tyler, 2004; Wyttenbach et al., 1998).

Table 7

Transfer factor (TF) values and TF statistics results for rice samples from Kočani Field $(\mathrm{La}-\mathrm{Sm}) \times 10-4$.

\begin{tabular}{lllllll}
\hline Soil & Rice & TF La & TF Ce & TF Pr & TF Nd & TF Sm \\
\hline I-1 & R-1 & 4.46 & 4.37 & 4.74 & 3.89 & 3.83 \\
I-3 & R-2 & 2.92 & 3.32 & 3.1 & 2.41 & 2.64 \\
I-5 & R-3 & 4.74 & 4.88 & 4.74 & 4.28 & 5.08 \\
II-1 & R-4 & 6.44 & 6.43 & 6.34 & 5.98 & 5.95 \\
II-5 & R-5 & 3.65 & 3.64 & 3.81 & 3.11 & 3.73 \\
III-1 & R-6 & 3.61 & 3.42 & 3.46 & 2.74 & 2.57 \\
III-5 & R-7 & 3.47 & 3.71 & 3.57 & 3.31 & 4.19 \\
IV-7 & R-8 & 3.26 & 3.11 & 3.56 & 2.91 & 3.14 \\
V-1 & R-9 & 3.7 & 4.12 & 3.79 & 4.03 & 5 \\
V-3 & R-10 & 2.25 & 2.07 & 1.65 & 2.12 & 2.5 \\
VI-1 & R-11 & 9.56 & 10.14 & 9.53 & 8.57 & 9.33 \\
VI-4 & R-12 & 4.98 & 4.72 & 5.13 & 4.1 & 3.91 \\
VII-2 & R-13 & 2.88 & 2.98 & 3.42 & 2.57 & 3.33 \\
VII-4 & R-14 & 8.57 & 8.96 & 8.87 & 8.23 & 10.56 \\
Statistics & Mean & 4.61 & 4.71 & 4.69 & 4.16 & 4.7 \\
& Median & 3.68 & 3.92 & 3.8 & 3.6 & 3.87 \\
& Minimum & 2.25 & 2.07 & 1.65 & 2.12 & 2.5 \\
& Maximum & 9.56 & 10.14 & 9.53 & 8.57 & 10.56 \\
& Std. dev. & 2.17 & 2.31 & 2.2 & 2.05 & 2.45 \\
\hline
\end{tabular}



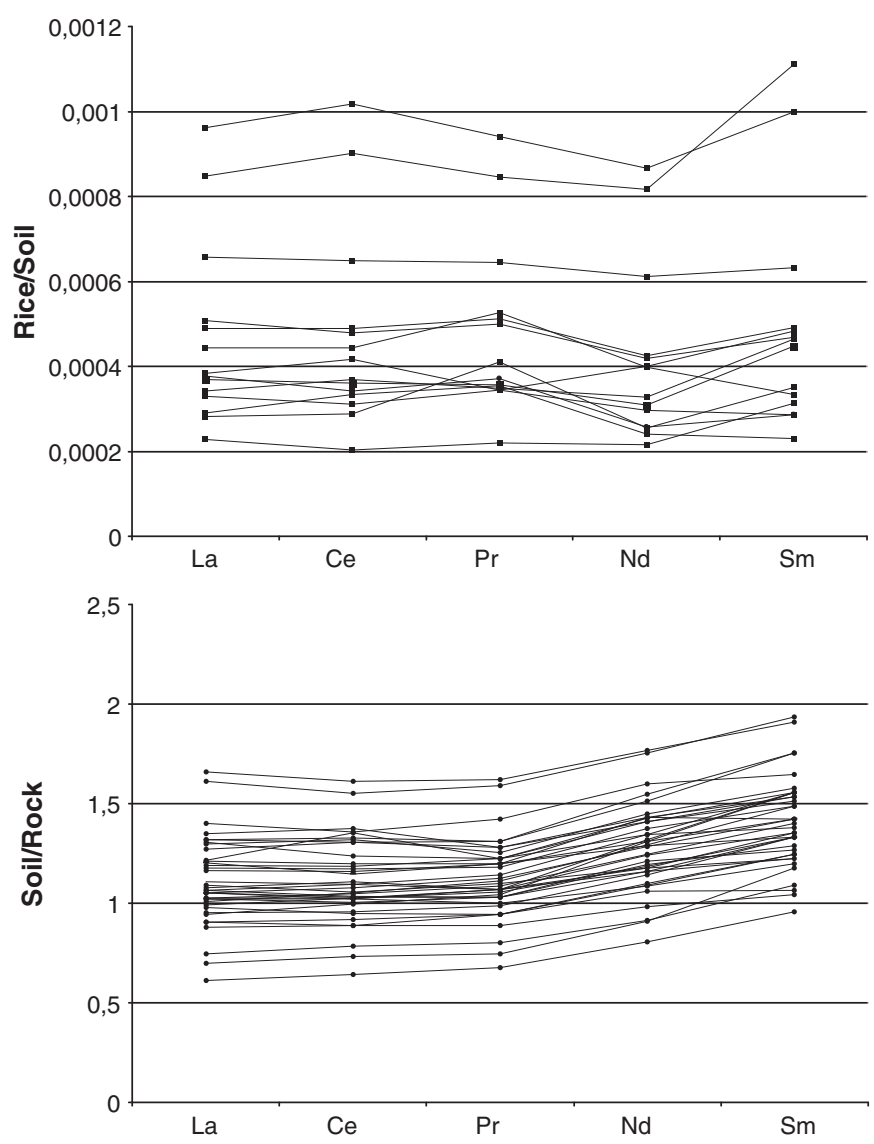

Fig. 6. REE patterns normalised to paddy soil samples/rice samples and to upper continental crust/paddy soil samples.

\section{Conclusions}

The elevated concentrations of REEs in paddy soil samples of Kočani Field are associated with the contribution to soil formation of the acidic and intermediate igneous rocks lithologies that prevail in the area.

The absolute concentrations of REEs ( $\mathrm{La}-\mathrm{Sm})$ in unpolished rice samples from Kočani Field were up to $6.6 \times 10^{3}$ times lower than those detected in the paddy soils. Additionally, results of a sequential extraction procedure showed that low percentages of REEs were bound to the water-soluble and exchangeable fractions. Therefore, REEs could be accumulated and retained by the roots, and only a small portion of the REEs reached the higher parts (grains) of rice plants.

The TF values of REEs in rice were also very low, confirming weak accumulation of REEs ( $\mathrm{La}, \mathrm{Ce}, \mathrm{Pr}, \mathrm{Nd}$, and $\mathrm{Sm}$ ) by rice crops. The upper continental crust normalised pattern for La-Sm in soils and the normalised pattern for La-Sm in soil/rice revealed deviations between $\operatorname{Pr}$ (higher) and Nd (lower) values, suggesting different fractionation events between these elements in the soil/plant system.

Possible anthropogenic effects will be evaluated in a future study.

\section{Table 8}

Pearson's correlation coefficients between REEs in soil and rice samples (marked correlations are significant at $p<0.05$ ).

\begin{tabular}{llllll}
\hline Rice/soil (S) & La $(S)$ & Ce $(S)$ & $\operatorname{Pr}(S)$ & Nd $(S)$ & Sm (S) \\
\hline La & 0.00 & -0.01 & -0.02 & -0.12 & -0.08 \\
Ce & 0.04 & 0.02 & 0.01 & -0.09 & -0.06 \\
Pr & -0.04 & -0.05 & -0.06 & -0.15 & -0.09 \\
Nd & 0.00 & -0.01 & -0.03 & -0.12 & -0.08 \\
Sm & 0.01 & -0.02 & -0.05 & -0.15 & -0.12 \\
\hline
\end{tabular}

\section{Acknowledgements}

This research was financially supported by the Slovenian Research Agency (ARRS), contract number 1000-05-310229. Critical reviews by two anonymous reviewers were greatly appreciated.

\section{References}

Aubert, D., Probst, A., Sille, P., 2004. Distribution and origin of major and trace element (particularly REE, $\mathrm{U}$ and $\mathrm{Th}$ ) into labile and residual phases in an acid soil profile (Vosges Mountains, France). Applied Geochemistry 19, 899-916.

Brown, P.H., Rathjen, A.H., Graham, R.D., Tribe, D.E., Karl, A.G., Schneidner, J.A.L.E., 1990 Rare Earth Elements in Biological Systems (Handbook on the Physics and Chemistry of Rare Earths, Chapter 92). Elsevier, Amsterdam, pp. 423-452.

Chen, Z.C., 1993. A investigation of living beings affected by leaching water of rare earth mine waste residue and their rare earth concentrations. Journal of Rare Earths (in Chinese) 14, 43-46.

Cui, Y.J., Zhu, Y.G., Zhai, R.H., Chen, D.Y., Huang, Y.Z., Qui, Y., 2004. Transfer of metals from soil to vegetables in an area near a smelter in Nanning, China. Environment International 30 (6), 785-791.

Dean, J.R., 2007. Bioavailability, Bioaccessibility and Mobility of Environmental Contaminants, first ed. John Wiley and Sons Ltd., England.

Ding, S.M., Liang, T., Zhang, C.S., Wang, L.J., Sun, Q., 2006. Accumulation and fractionation of rare earth elements in a soil-wheat system. Pedosphere 16, 82-90.

Dolenec, T., Serafimovski, T., Tasev, G., Dobnikar, M., Dolenec, M., Rogan, N., 2007. Major and trace elements in paddy soil contaminated by $\mathrm{Pb}-\mathrm{Zn}$ mining: a case study of Kočani Field, Macedonia. Environmental Geochemistry and Health 29, 21-32.

Egashira, K., Fujii, K., Yamasaki, S., Virakornphanich, P., 1997. Rare earth element and clay minerals of paddy soils from the central region of the Mekong River, Laos. Geoderma 78, 237-249.

Filgueiras, A.V., Lavilla, I., Bendicho, C., 2002. Chemical sequential extraction for metal partitioning in environmental solid samples. Journal of Environmental Monitoring 4, 823-857.

Fuentes, A., Llorens, M., Saez, J., Soler, M., Ortuno, J., Meseguer, V., 2004. Simple and sequential extraction of heavy metals from different sewage sludges. Chemosphere $54,1039-1047$.

Han, G., Liu, C., 2006. Dissolved rare earth elements in river waters draining karts terrains in Guizhou Province, China. Aquatic Geochemistry 13 (1), 95-107.

Henderson, P., 1984. About rare elements. In: Henderson, P. (Ed.), Rare Earth Element Geochemistry. Elsevier, New York, pp. 1-50.

Herman, A.G., 1970. Ytrium and lanthanides. In: Wedepohl, K.H. (Ed.), Handbook of Geochemistry. Springer-Verlag, Berlin, pp. 57-71.

Hong, F.H., Wei, Z.G., Zhao, G.W., 2000. Effect of lanthanum on aged seed germination of rice. Biological Trace Element Research 75, 205-213.

Hu, Z., Haneklaus, S., Sparovek, G., Schnug, E., 2006. Rare earth elements in soils. Communications in Soil Science and Plant Analysis 37 (9-10), 1381-1420.

Ichihashi, H., Morita, H., Tatsukawa, R., 1992. Rare earth elements in naturally grown plants in relation to their variation in soils. Environmental Pollution 76, 157-162.

Kabata-Pendias, A., Pendias, H., 2001. Trace Elements in Soils and Plants, third ed. CRC Press, Boca Raton, pp. 1-413.

Kazi, T., Jamali, G., Kazi, G., Arain, M., Afridi, H., Siddiqui, A., 2002. Evaluating the mobility of toxic metals in untreated industrial wastewater sludge using a BCR sequential procedure and a leaching test. Analytical and Bioanalytical Chemistry 374, 255-261.

Laveuf, C., Cornu, S., 2009. A review on the potentiality of rare earth elements to trace pedogenetic processes. Geoderma 154, 1-12.

Li, X.D., Coles, B.J., Ramsey, M.H., Thorton, I., 1995. Sequential extraction of soils for multielement analysis by ICP-AES. Chemical Geology 124, 109-123.

Li, F., Shan, X., Zhang, T., Zhang, S., 1998. Evaluation of plant availability of rare earth elements in soils by chemical fractionation and multiple regression analysis. Environmental Pollution 102, 269-277.

Markert, B., Zhang, D.L., 1991. Natural background concentrations of rare earth elements in a forest ecosystem. Science of the Total Environment 103, 127-135.

Protano, G., Riccobono, F., 2002. High contents of rare earth elements (REEs) in stream waters of a $\mathrm{Cu}-\mathrm{Pb}-\mathrm{Zn}$ mining area. Environmental Pollution 117, 499-514.

Reiman, C., Caritat, P., 1998. Chemical elements in the Environment, ed. Springer-Verlag, Berlin.

Rogan Šmuc, N., 2010. Heavy metal contamination of soils and crops in teriary basins: a case study of Kočani Field (Macedonia). Ljubljana, Slovenija - Dr thesis, 108 pp.

Rogan, N., Serafimovski, T., Dolenec, M., Tasev, G., Dolenec, T., 2009. Heavy metal contamination of paddy soils and rice (Oryza sativa L.) from Kočani field (Macedonia). Environmental Geochemistry and Health 31, 439-451.

Ross, G.R., Guevara, S.R., Arribere, M.A., 1995. Rare earth geochemistry in sediments of the Upper Manso River Basin, Rio Negro, Argentina. Earth and Planetary Science Letters $133,47-57$

Serafimovski, T., Aleksandrov, M., 1995. Lead and zinc deposits and occurrences in the Republic of Macedonia. Special edition of RGF, with extended summary in English, Stip.

Serafimovski, T., Tasev, G., Dolenec, T., 2005. Petrological and Geochemical Features of the Neogene Volcanites of the Osogovo Mountains, Eastern Macedonia. RMZ - Materials and Geoenvironment 52, 523-534.

Taylor, S.R., McLennan, S.M., 1995. The geochemical evolution of the continental crust. Reviews of Geophysics 33, 611-627.

Tessier, A., Campbell, P.G.C., Bisson, M., 1979. Sequential extraction procedure for the speciation of particulate trace metals. Analytical Chemistry 51, 844-851. 
Tsumura, A., Yamasaki, S., 1993. Behaviour of uranium, thorium and lanthanides in paddy fields. Radioisotopes 42, 265-272.

Tyler, G., 2004. Rare earth elements in soil and plant systems - a review. Plant and Soil $267(1-2), 191-206$

Ure, A.M., Bacon, J.R., 1979. Comprehensive analyses of soils and rocks by spark-source mass spectrometry. Analyst 103, 807.

Wang, X.R., 1991a. Present status and trends on environmental chemical behaviour of rare earth elements. Environmental Chemistry (in Chinese) 10, 73-74.

Wang, H.K., 1991b. Advances of metal pollution study in soils. Environmental Chemistry (in Chinese) 10, 39.

Wang, L.J., Zhang, S., Gao, X.J., Liu, S.J., Wang, Y.Q., Sun, J.X., Hu, A.T., Chen, H.M., Gao, F.Q., 1998. Geochemical characteristics of rare earth elements in different types of soils in China. Journal of Rare Earths 19 (1), 51-67.

Wang, Y., Wang, J., Wang, L., Wang, Y., Tu, C., 2004. REE characteristics of the Kalatongke Cu-Ni deposit, Yinjiang, China. Acta Geologica Sinica 78, 396-403.

Wedepohl, K.H., 1995. The composition of the continental crust. Geochimica et Cosmochimica Acta 59, 1217-1232.
Wyttenbach, A., Furrer, V., Schleppi, P., Tobler, L., 1998. Rare earth elements in soil and in soil-grown plants. Plant and Soil 199, 267-273.

Xu, X., Zhu, W., Wang, Z., Witkamp, G.J., 2002. Distributions of rare earths and heavy metals in field-grown maize after application of rare earth-containing fertilizer. Science of the Total Environment 293, 97-105.

Yoshida, S., Muramatsu, Y., Tagami, K., Uchida, S., 1998. Concentrations of Lanthanide elements Th, and U in 77 Japanese surface soils. Environment International 24, 275-386.

Yuan, D., Shan, X.Q., Huai, Q., Wen, B., Zhu, X., 2001. Uptake and distribution of rare earth elements in rice seeds cultured in fertilizer solution of rare earth elements. Chemosphere 43, 33-44.

Zhu, Q.Q., Liu, Z., 1988. REEs in soils of eastern China. Journal of the Chinese Rare Earth Society (in Chinese) 6 (4), 59-65.

Zhu, J.G., Xing, G.X., 1992. Sequential extraction procedure for the speciation of REEs in soils. Soils (in Chinese) 24 (4), 214-218. 